\title{
Variation and Evolution in the Karyotype of Lycoris, Amaryllidaceae VII. Modes of karyotype alteration within species and probable trend of karyotype evolution in the genus
}

\author{
Siro Kurita \\ Department of Biology, Faculty of Science, Chiba University, \\ Yayoicho 1-33, Chiba, 260 Japan
}

Accepted May 2, 1987

As to the trend of karyotype evolution in Lycoris, Inariyama (1951a, 1951b) proposed a fusion hypothesis. He considered that the various karyotypes of fertile diploid species of this genus must have had their origin in the karyotype of $L$. sanguinea composed of twenty-two I-shaped (acrocentric sensu lato) chromosomes alone, and the most advanced karyotype of $L$. aurea composed of ten V-shaped (meta- or submetacentric) chromosomes and two I-shaped chromosomes were derived from the former by successive fusions of any two I-shaped chromosomes. While he considered that the karyotypes of sterile species such as $L$. albiflora, $L$. squamigera and $L$. radiata were produced by hybridization and/or polyploidization. Nmaely, in his opinion, the basic chromosome number of Lycoris is not $\mathrm{x}=6$, the lowest haploid number in the genus, but $x=11$. Recently, Jones (1978) and Nishikawa et al. (1979) supported Inariyama's hypothesis. On the other hand, however, Darlington (1963) and Flory (1977) considered that I-shaped chromosomes must have been originated from the fission through the centromeric region of $\mathrm{V}$-shaped chromosomes in this genus.

Instead of I-shaped and V-shaped chromosomes, the present author recognized three major types of chromosome, $M, T$ and $A$ (1986). Moreover he observed various types of intraspecific structural and numerical chromosomal changes of the karyotype involving some mutant chromosomes such as $M^{\prime}, T^{\prime}, m$ and $a$ (Kurita 1987a, 1987b, 1987c, 1988c). In this paper, he summarizes and itemizes the modes of karyotype alterations, and then the problem of the trend of karyotype evolution in this genus is discussed based on his observations and the data obtained by many previous cytologists.

The chromosome numbers of Lycoris species so far known are summarized in Table 1.

I) Modes of the karyotype alterations

1: Shortening of short arm of the standard $A$ type chromosome resulting $T^{\prime}$ type chromosome (Fig. 1-a) was observed in many bulbs of $L$. sanguinea complex (Kurita 1988a, 1988c).

2: Shortening of long arm of the $A$ type chromosome (Fig. 1-a) was observed in some bulbs of L. sanguinea complex (Kurita 1988a, 1988c) and L. radiata var. radiata (Kurita 1987c).

3: Elongation of short arm of the $A$ type chromosome resulting a subtelocentric chromosome (Fig. 1-a) was observed in many bulbs of $L$. sanguinea complex (Kurita 1988a, 1988c).

4: Elongation of long arm of the $A$ type chromosome (Fig. 1-a) was found in a bulb of L. sanguinea var. sanguinea (Kurita 1988c).

5: Formation of $M^{\prime}$ and $m$ type chromosome by means of Robertsonian fusion of two $A$ type chromosomes (Fig. -b) was observed in some bulbs of $L$. radiata var. radiata (Kurita 1987c).

6: Elimination of the $m$ type chromosome (Fig. 1-b) was observed in some bulbs of $L$. 
Table 1. Chromosome numbers of the genus Lycoris

\begin{tabular}{|c|c|c|}
\hline Taxa & $2 n$ & Authors** \\
\hline \multirow[t]{4}{*}{ L. aurea (L'Hérit) Herb.* } & 12 & $\begin{array}{l}\text { Inarityama 1931, Bose } 1985 \text {, Koyama 1962, Yoshida } \\
\text { 1972, Takemura 1962, Bose and Flory } 1963\end{array}$ \\
\hline & 13 & $\begin{array}{l}\text { Inariyama 1932, } 1937,1951,1953 \text {, Koyama } 1962, \\
\text { Takemura 1962, Bose and Flory 1963, Yoshida 1972, } \\
\text { Nishikawa et al. } 1979 \text {, Ueno } 1983\end{array}$ \\
\hline & 14 & Inariyama 1932, 1937, 1951, 1953, Takemura 1962 \\
\hline & 15 & Bose 1958, Bose and Flory 1963, Kurita 1987 \\
\hline \multirow[t]{3}{*}{ L. traubii Hayward } & 12 & Bose 1958, Bose and Flory 1963, Kurita 1987 \\
\hline & 13 & Bose 1958, Bose and Flory 1963, Kurita 1987 \\
\hline & 14 & Kurita 1987 \\
\hline L. "Sperryi" & 15 & Bose 1960 \\
\hline L. chinensis Traub. & 16 & Bose 1960, Bose 1966, Hsu et al. 1984 \\
\hline L. straminea Lindl. & 16 & $\begin{array}{l}\text { Inariyama 1937, 1951, 1953, Takemura 1961, Kurita } \\
1987\end{array}$ \\
\hline L. anhweiensis Hsu et Fan & 16 & Hsu et al. 1984 \\
\hline L. longituba Hsu et Fan & 16 & Hsu and Huang 1984 \\
\hline \multirow[t]{3}{*}{ L. albiflora Koidzumi } & 16 & Inariyama 1931 \\
\hline & 17 & $\begin{array}{l}\text { Inariyama } 1931,1932,1937,1951,1953 \text {, Bose } 1959 \text {, } \\
\text { 1963, Koyama 1962, Takemura } 1962, \text { Bose and Flory } \\
\text { 1963, Yoshida 1972, Nishikawa et al. } 1979 \text {, Kurita } \\
\text { 1986 }\end{array}$ \\
\hline & 18 & Inariyama 1931 \\
\hline L. elisiae Traub. & 17 & Bose 1960, Bose and Flory 1963 \\
\hline L. rosea Traub et Moldenke & 22 & Hsu and Huang 1984 \\
\hline L. haywardii Traub & 22 & Bose 1957, 1958, Bose and Flory 1963, Hsu et al. 1984 \\
\hline $\begin{array}{l}\text { L. radiata (L'Hérit) Herb. var. } \\
\text { pumila Gray }\end{array}$ & 22 & $\begin{array}{l}\text { Nishiyama 1939, Inariyama 1951, 1953, Takemura } \\
\text { 1962, Yoshida } 1972 \text {, Nishikawa et al. 1979, Hsu et al. } \\
\text { 1984, Kurita } 1987\end{array}$ \\
\hline \multirow[t]{2}{*}{$\begin{array}{l}\text { L. sanguinea Maxim. var. } \\
\text { sanguinea }\end{array}$} & 22 & $\begin{array}{l}\text { Nishiyama } 1928 \text {, Inariyama } 1931,1937,1951,1953 \text {, } \\
\text { Sato 1942, Takemura 1961, 1962, Bose and Flory } \\
1963 \text {, Yoshida } 1972 \text {, Nakamura 1978, Koyama } 1954 \text {, } \\
1962 \text {, Kurita } 1988\end{array}$ \\
\hline & $\begin{array}{l}23 \\
32\end{array}$ & $\begin{array}{l}\text { Kurita } 1988 \\
\text { Kurita } 1988\end{array}$ \\
\hline \multirow{3}{*}{$\begin{array}{l}\text { L. sanguinea Maxim. var. } \\
\text { kiushiana Makino }\end{array}$} & 22 & $\begin{array}{l}\text { Kurita } 1988 \\
\text { Takemura, 1965, Yoshida 1972, Kurita } 1988\end{array}$ \\
\hline & 33 & Kurita 1988 \\
\hline & 44 & Kurita 1988 \\
\hline $\begin{array}{l}\text { L. sanguinea Maxim. var. koreana } \\
\text { (Nak.) Koyama }\end{array}$ & 22 & Takemura 1965, Kurita 1988 \\
\hline L. sprengeri Comes ex Baker & 22 & $\begin{array}{l}\text { Inariyama } 1937,1951,1953 \text {, Takemura } 1961,1962, \\
\text { Koyama } 1962, \text { Yoshida } 1972 \text {, Nishikawa et al. } 1979 \text {, } \\
\text { Hsu et al. } 1981 \text {, Kurita } 1987\end{array}$ \\
\hline L. "cinnabarina" & $22+B$ & Esterly 1969 \\
\hline L. caldwellii Traub & 27 & Bose 1957, Bose and Flory 1963 \\
\hline \multirow[t]{2}{*}{ L. squamigera Maxim. } & 26 & Khaleel 1978 \\
\hline & 27 & $\begin{array}{l}\text { Takenaka } 1930 \text {, Inariyama } 19311937,1951,1953 \text {, } \\
\text { Sato } 1938,1942 \text {, Bose } 1958 \text {, Bose and Flory } 1963, \\
\text { Takemura 1961, Koyama 1962, Nakamura 1978, } \\
\text { Nishikawa et al. 1979, Kurita } 1987\end{array}$ \\
\hline L. incarnata Spreng. & $\begin{array}{l}29+B \\
30\end{array}$ & $\begin{array}{l}\text { Bose } 1958, \text { Bose and Flory } 1963 \\
\text { Kurita } 1987\end{array}$ \\
\hline L. houdyshelii Traub & 30 & Bose 1957, Bose and Flory 1963, Kurita 1987 \\
\hline \multirow[t]{4}{*}{ L. radiata (L'Hérit) Herb. } & 28 & Lee 1967 \\
\hline & 32 & Kurita 1987 \\
\hline & $32+B$ & Bose 1963 \\
\hline & 33 & $\begin{array}{l}\text { Nishiyama 1928, Inariyama 1931, 1937, 1951, 1953, } \\
\text { Kihara and Koyama 1954, Koyama 1954, 1959, 1962, } \\
\text { Mookerjea } 1955 \text {, Bose } 1958 \text {, Bose and Flory 1963, } \\
\text { Fukuda et al. } 1980, \text { Hsu et al. } 1984 \text {, Kurita } 1987\end{array}$ \\
\hline
\end{tabular}

* Materials which were examined by Japanese cytologists were not L. aurea but $L$. traubii in fact as it was discussed in the prevoius paper (Kurita 1980, 1987a).

** See the references in the previous paper (Kurita 1986). 
radiata var. radiata and $L$. sanguinea var. sanguinea (Kurita 1987c, 1988c).

7: Formation of $a$ or $m$ type chromosome with acentric chromosome (Fig. 1-b) was observed in a bulb of $L$. sanguinea var. sanguinea (Kurita 1988c).

8: Formation of dicentric chromosome (Fig. 1-b) was observed in a bulb of L. sanguinea var. sanguinea (Kurita $1987 \mathrm{c}$ ).

9: Formation of $\boldsymbol{A}$ type chromosome from $T$ type chromosome (Fig. 1-c) was presumed in the karyotype of L. straminea and L. aurea (Kurita 1987a).

10: Formation of submetacentric chromosome from $T$ type chromosome (Fig. 1-e) was also presumed in the karyotype of $L$. chinensis (Bose 1966).

11: Formation of $A$ type from $M$ type chromosome (Fig. 1-d) was observed in a bulb of L. traubii (Kurita 1987b).

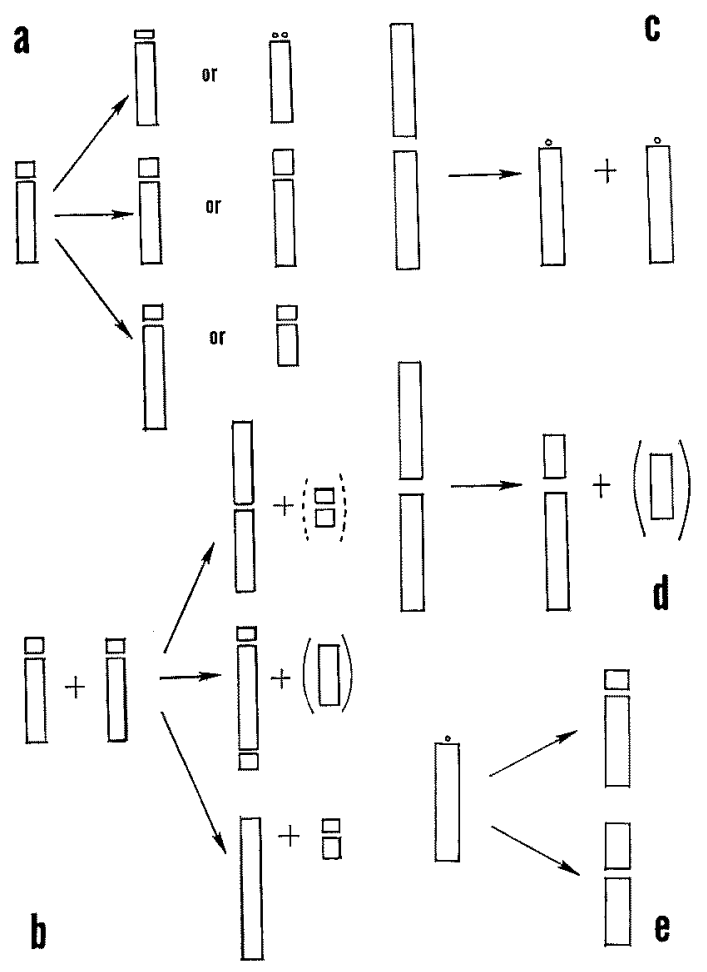

Fig. 1. Observed and presumed alterations of chromosome form and size in the genus Lycoris (cf. text).

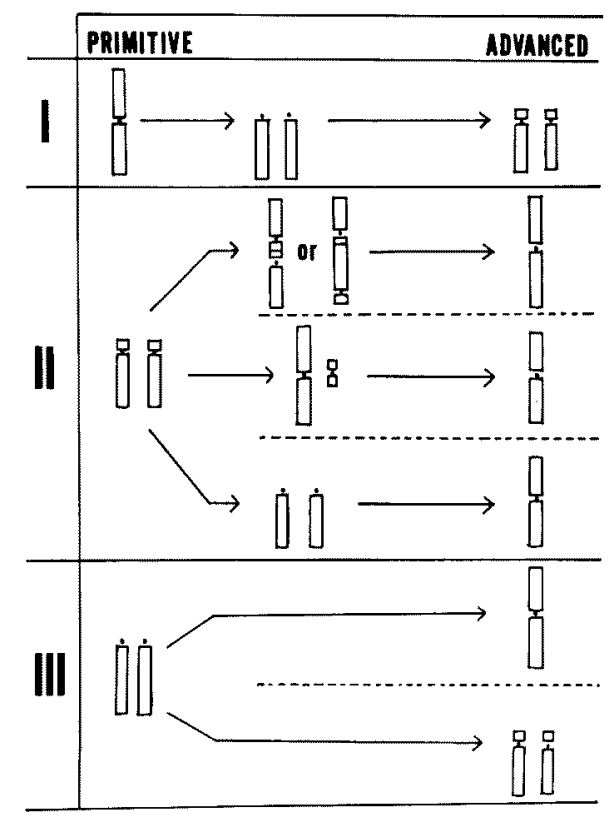

Fig. 2. Three probable hypotheses for the karyotype evolution in the genus Lycoris (cf. text).

12: Formation of two $T$ type chromosomes from one $M$ type chromosome by centric fission (Fig. 1-c) was observed in the pollen mother cells of L. traubii, L. albiflora and L. squamigera (Koyama 1967, 1978).

13: Heterochromatinization of the proximal region of the $T$ type chromosomes and successive release of this region were supposed (Kurita 1986, 1987a, b).

II) Evolution of the karyotype

1) Three probable hypotheses

On the basis of comparative studies of the karyotypes of the taxa examined, it is possible to suppose three main direction of the karyotype evolution theoretically (Fig. 2). 
In the first instance, the line I of the figure, $M$ type chromosome is supposed to be ancestral type, and it changes into two $T$ type chromsomes by direct centric fission. After this, $T$ changes into $A$ type chromosome by pericentric inversion. Therefore, in this case, the basic chromosome number of the genus is considered to be $\mathrm{x}=6$. This is the haploid number of L. traubii.

In the second instance, the line II, $A$ type chromosomes are supposed to be ancestral and then three following courses to attain to $M$ type chromosome can be drawn. The upper row of the line II is the case of end-to-end tandem fusion. The middle row is the case of standard Robertsonian fusion and the bottom row shows pure centric association of two telocentrics which are produced from the ancestral $A$ type chromosomes by pericentric inversion or translocation.

In the third instance, the line III, $T$ type chromosomes are supposed to be ancestral and they change into $M$ type or $A$ type chromosomes by simple centric fusion (upper row) or pericentric inversion (lower row).

2) Exploration of the possiblitity of the hypotheses.

Inariyama (1951) was the first cytologist who discussed the karyotype evolution in Lycoris. He had recognized two types of chromosome, V-shaped and I-shaped, and proposed fusion hypothesis. He concluded as follows: In Lycoris the basikaryotype, $11 \mathrm{I}$, is original one, and the other basikaryotype, $5 \mathrm{~V}+1 \mathrm{I}$, is an extreme type derived from the original type by successive chromosome fusion leaving one I-shaped chromosome. In his opinion, this conclusion is supported by the fact that the species having the basic chromosome number of 11 has been known far more numerous than those having $x=6$ in the Amaryllidaceae. Thereafter, however, many data of chromosome numbers of the family have been acumulated and many taxa based on $x=6$ are known at present. Therefore it does not necessarily to adhere to $x=11$.

The upper row in the line II of the figure 2 shows Inariyama's fusion hypothesis diagramatically. The tandem fusion of chromosomes is a special type of translocation and it has been reported in a few of animals and plants. It was demonstrated using G-banding method that the chromosome number of 26 of Indian spiny mouse, Mus platythrix, was originnated from the standard karyotype having $2 \mathrm{n}=42$ of the feral mouse, Mus musculus, by this type of tandem fusion (Yoshida 1980). In this case, the total chromosome length was about $12.8 \%$ shorter in the spiny mouse than in the feral mouse. This suggests that some chromosome parts including telomeres and centromeres must have been lost during the processes of tandem fusion. Very large and small numbered chromosomes of Indian muntjac $(2 n=6$, female $)$ is also believed to be a product of sequential tandem fusion of many chromsomes of barking deer $(2 n=46)$. In this case, centromeres and telomeres must have been lost during the process too, since the DNA content of Indian muntjac was 30\% less than that of barking deer (Wurster and Benirschke 1970).

Inariyama (1951), on the other hand, did not supposed any loss of any part of chrcmosomes in his end-to-end fusion theory. In this case, formed chromosomes are sure to have two centromeric regions inevitably. Dicentric chromosome, which has been observed in a bulb of L. sanguinea var. sanguinea, is considered to be unstable and it will be lost sooner or later as reported in many organisms. Therefore, it must change into monocentric chromosome by inactivation of one centromere as soon as possible to survive in the following cell line. Though there are some instances in animals, no concrete and positive evidence of such inactivation of centromere is known in plants. However, the large chromosome of Haplopappus gracilis of which karyotype was analysed precisely by Tanaka (1967) is somewhat suggestive in this connection. The karyotype of $H$. gracilis $(2 \mathrm{n}=4)$ was considered to be produced by tandem fusion of some chromosomes in the genome of $H$. ravenii $(2 \mathrm{n}=8)$, but Tanaka did not ditect any difference in their total chromosome length. Therefore, two centrometic regions of $H$. ravenii 
were considered to be inactivated in the newly formed large chromosome of $H$. gracilis.

In any case mentioned above, total chromosome length or DNA content of derived karyotype is always shorter or lesser than that of the ancestral one or is equivalent at the most so far known. This is also true in the case of the middle and bottom row in the line II. Typical Robertsonian fusion, the middle row, was observed in $L$. radiata var. radiata (Kurita 1987c). Namely two $A$ type chromosomes had associated at centromeric region and tansformed into one $M^{\prime}$ type and one $m$ type chromosome. Robertsonian fusion is very common on the occasion of transformation of karyotypes of both animals and plants (Chiarelli and Capanna 1973, Yoshida 1983, White 1973, Imai et al. 1977, Stebbins 1971, and Jones 1978). Especially

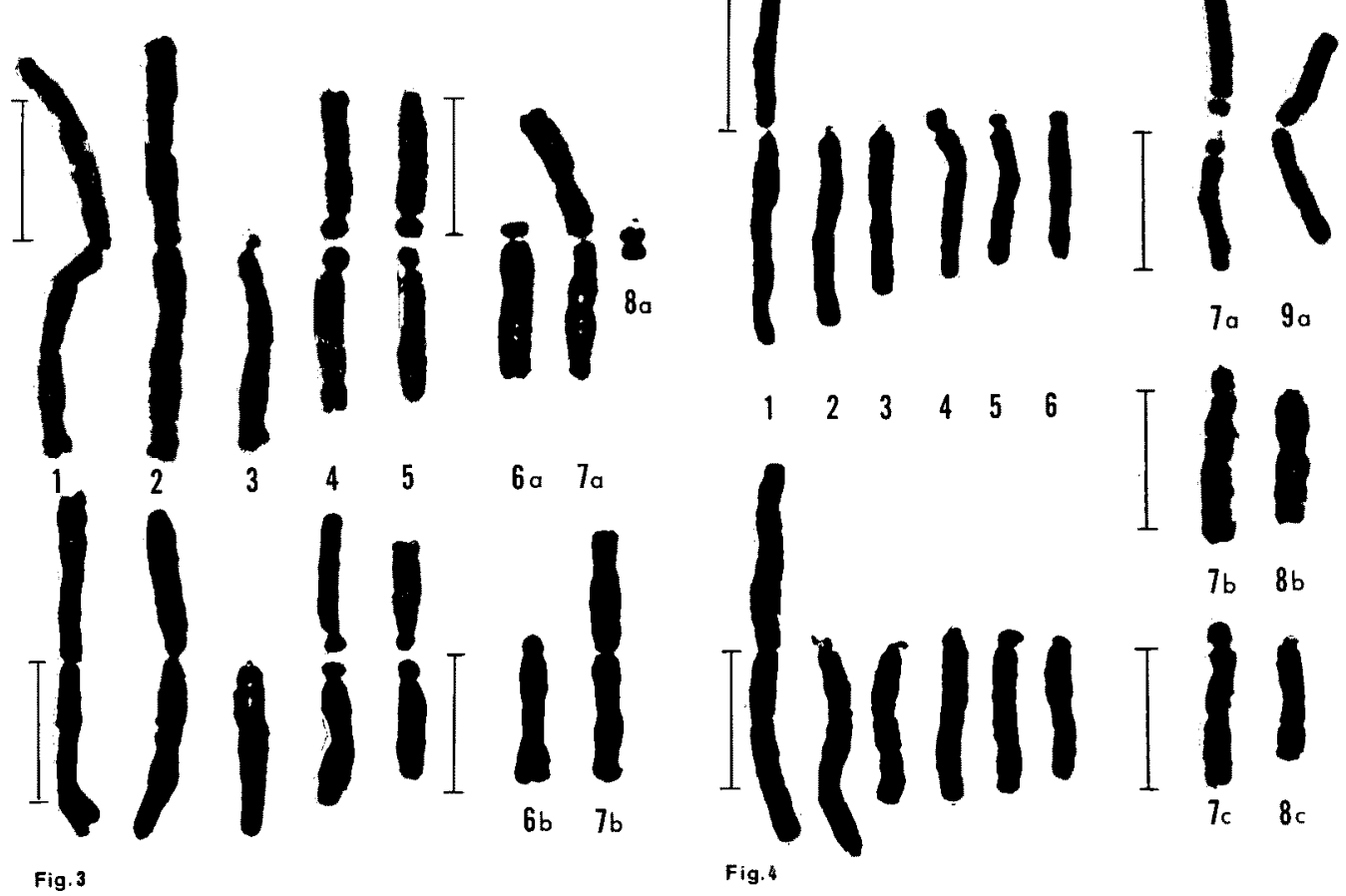

Figs. 3-4. 3, partial karyotypes of $L$. albiflora and $L$. radiata var. radiata, showing $M$ type (1 and 2), $T$ type (3) and $A$ type chromosomes ( 4 and 5 ) in the complements of $L$. albiflora; and $A$ type (6a and $6 \mathrm{~b}$ ), $M^{\prime}$ type (7a and $7 \mathrm{~b}$ ) and $m$ type chromosome (8a) in the complements of $L . r$. var. radiata obtained from Uematsu (a) and Nagasaki (b). Association of two $A$ type chromosomes by means of Robertsonian fusion produces $M^{\prime}$ type chromosome, not $M$ type chromosome. 4, partial karyotype of $L$. squamigera and $L$. sanguinea complex, showing $M$ type (1), $T$ type (2 and 3 ), $A$ type chromosomes (4,5 and 6) in two complements of $L$. squamigera; and $A$ type (7a, $7 \mathrm{~b}$ and $7 \mathrm{c}$ ), $T^{\prime}$ type ( $8 \mathrm{~b}$ and $8 \mathrm{c}$ ) and $M^{\prime}$ type chromosome (9a) in three complements of $L$. sanguinea complex obtained from Honjo (a), Taradake (b) and Hoshikura (c). Bars indicate $70 \mu \mathrm{m}$.

Jones (1978) claimed that $M$ type chromosomes of Lycoris species were produced by this way, but his conclusion was beside the point in this case. This problem will be discussed fully later. Again it is noteworthy that the length of $M^{\prime}$ type chromosome is always shorter than the sum of two original $A$ type chromosomes.

The formation of $M$ type chromosome by centric fusion of two $T$ type chromosomes (Fig. 2, bottom row of line II) was not observed in Lycoris. Jones (1978) however, reported such instance in Zebrina, Commelinaceae, where $T$ (or $T^{\prime}$ ) type chromosomes fused at centromeric point and then $M$ (or $M^{\prime}$ ) type chromosomes were produced. The principle of "one 
and one equals two" was also available in this case as to the length of chromosomes.

Is the fusion hypothesis acceptable for the karyotype evolution of Lycoris? It is not acceptable in the author's opinion based on the present studies.

As is indicated by the following comparative figures, $M$ type chromosome of Lycoris is not simple product of Robertsonian fusion or end-to-end tandem fusion of two $A$ type or $T^{\prime}$ type chromosomes. Figure 3 shows $M$ type ( 1 and 2), $T$ type (3), and $A$ type chromosome (4 and 5) selected from the complement of two bulbs of $L$. albiflora; and $A$ type (6), $M^{\prime}$ type (7), and $m$ type chromosome (8) selected from the complements of two bulbs of $L$. radiata var. radiata. While figure 4 shows $M$ type (1), $T$ type (2 and 3), and $A$ type chromosomes (4, 5 and 6$)$ selected from the complements of two bulbs of $L$. squamigera; and $A$ type (7), $T^{\prime}$ type (8) and $M^{\prime}$ type chromosome (9) selected from the complements of three bulbs of $L$. sanguinea complex.

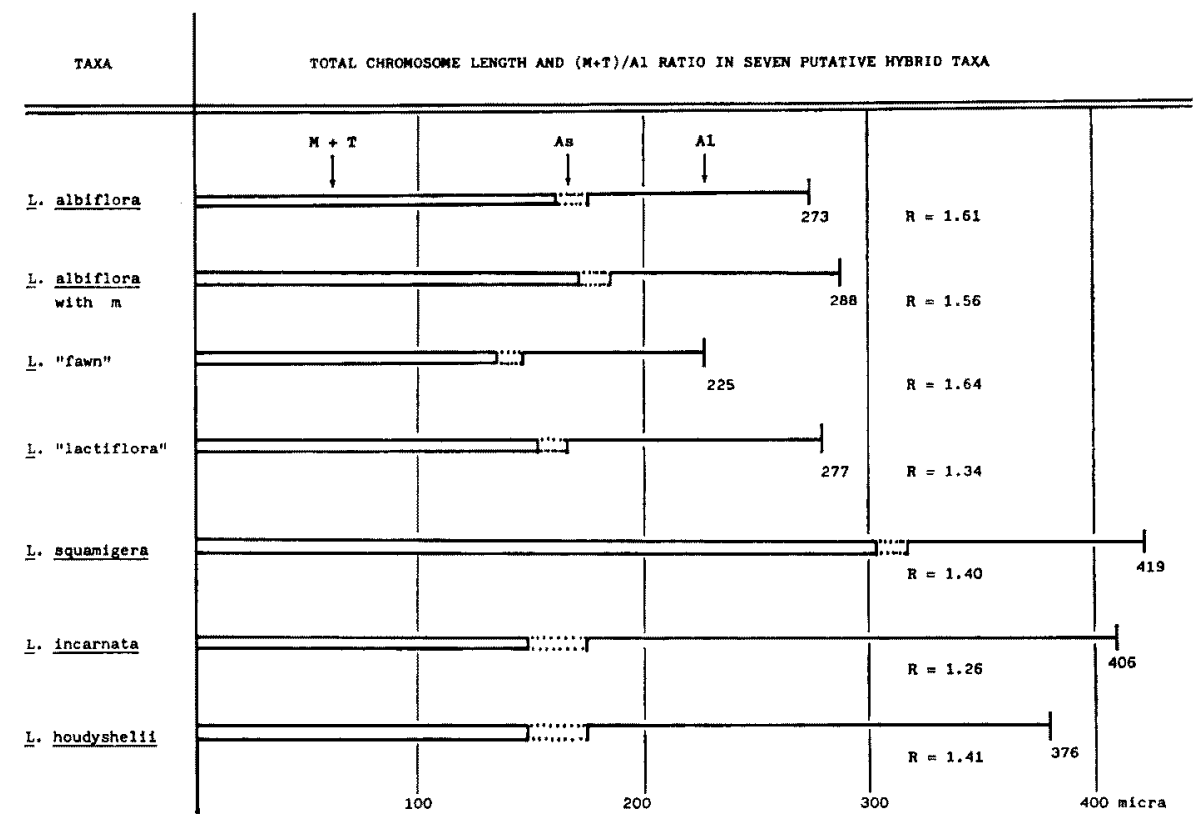

Fig. 5. Total chromosome length and $(M+T) / A l$ ratio $(R)$ in seven putative hybrid taxa of Lycoris. $\mathrm{M}+\mathrm{T}$ is total length of $M$ and $T$ type chromosomes in a complement, and As and $\mathrm{Al}$ is total length of short arms of $A$ type chromosomes and that of long arms of the type in the complement, respectively.

At a glance, it is clear that the length of every arm of $M$ and $T$ type chromosomes is longer than that of $A, M^{\prime}$ and $T^{\prime}$ type chromosomes, and $M^{\prime}$ is real product of Robertsonian fusion of two $A$ type chromosomes.

This situation is also clearly shown in Fig. 5. According to the karyotype analysis of six putative hybrid taxa having the karyotype consisting of $M, T$ and $A$ type chromosomes, the ratio $R$ of each taxon was calculated. $R$ equals $(\mathrm{M}+\mathrm{T}) / \mathrm{A} 1 . \mathrm{M}+\mathrm{T}$ is total chromosome length of the genome consisting of $M$ and $T$ type chromosomes and A1 is total length of the long arms of the genome consisting of $A$ type chromosomes (cf. Kurita 1987a). For example; $R$ value of $L$. albiflora and $L$. squamigera is 1.61 and 1.40 , respectively. As shown in this figure, each $R$ value of the seven taxa is always larger than 1.0.

Moreover, Nishikawa et al. (1979) reported that the DNA content of a genome consisting of $M$ and $T$ type chromosomes was larger than that of a genome consisting of $A$ type chromo- 
somes alone. These results strongly suggest that $M$ type chromosome is not a simple product of the fusion of two $A$ type chromosomes unlike $M^{\prime}$ type chromosome which was observed in $L$. sanguinea var. sanguinea and $L$. radiata var. radiata. In other words, Robertsonian fusion or end-to-end tandem fusion of $A$ type chromosomes can not produce any $M$ type chromosomes.

However, it can not be neglected thoroughly that the $M^{\prime}$ type chromosome which had been produced by Robertsonian fusion of $A$ type chromosomes changed into $M$ type by partial tandem duplication or "growth" of heterochromatin during the karyotype evolution of this genus.

In the course of macroevolution, DNA content increased certainly by doubling or polyploidization as suggested by Sparrow and Nauman (1976), and in the course of speciation, increment of DNA content also occurred in some plants and animals.

Usually the increment in the course of speciation has been resulted by polyploidy or successive unequal crossover (Smith 1876, Macgregor 1978). In the case of successive unequal crossover, some large chromosomes are produced with small ones, which are lost in the subsequent generations. However, the author supposes that the large $M$ type chromosomes of Lycoris species are not the products of successive unequal crossover, because he does not observe any aberrant metacentric chromosomes formed by such unequal crossover.

Another type of increment of DNA content or chromosome length has been known. It was styled "growth" of chromosome (Imai et al. 1977). As suggested by Hsu and Arrighi (1971), tandem redundancy as a "growth" of C-banding positive heterochromatic block at the particular region of chromosome was reported in some animals such as ants, black rats and grasshoppers (Imai et al. 1977, Yoshida 1983, John and King 1983). This type of size increment is also not the case of Lycoris, since no large and additional C-banding positive heterochromatic blocks are found in $M$ type chromosomes of the genus.

On the other hand, Schimke (1981) observed tandem gene amplification (redundancy) at one arm of no. 2 chromosome in the cultured cells of Chinese hamster, and this increased region was composed of the genes which were translated actively into mRNA for an enzyme. This finding may supply arguments for the saltatory replication hypothesis which was proposed by Britten and Kohne $(1967,1969)$ for the discontinuous increment of DNA content among some closely related species having almost the same chromosome numbers. If such type of increment or "growth" occurs at pericentric region of both arms of $M^{\prime}$ type chromosome, it may change into $M$ type chromosome. However, the author could not observe any example of such "growth" of $M^{\prime}$ type chromosome of the genus. The $M^{\prime}$ type chromosomes which had been formed by means of Robertsonian fusion of two $A$ type chromosomes were retained in any genome without any change.

In the line III, it is supposed that the ancetsral $T$ type chromosomes change into $M$ and $A$ type chromosomes. The $A$ type chromosome formation from $T$ type was observed in $L$. straminea and $L$. aurea, but the formation of $M$ type chromosome by means of centric fusion of two $T$ type chromosomes was not found in this genus so far studied. Moreover, the mean length of $T$ type chromosomes is somewhat shorter than that of every arm of $M$ type chromosomes in a given genome. For example: this difference is $0.85 \mu \mathrm{m}(9.0 \%$ of the mean length of the arms of $M)$ in L. straminea and $1.07 \mu \mathrm{m}(9.9 \%$ of the mean length of the arms of $M)$ in $L$. aurea. Therefore, if this line of karyotype evolution had occurred, partial tandem duplication or "growth" in each arm of newly formed metacentric chromosomes must have also been supposed. But there was no certain evidence in this connection.

On the contrary, the direction shown in the line I, $M \longrightarrow 2 T \longrightarrow 2 A$, seems to be more probable in the case of Lycoris. In this instance, there is no necessity for assuming the occurrence of any tandem "growth" of chromosomes, and the DNA content or total chromosome 
length of the genome gradually decreases in accompany with karyotype evolution or speciation.

The transformation of $M$ type to $T$ type chromosomes was observed at the first meiotic division of L. traubii, L. squamigera and $L$. albiflora (Koyama 1967, 1978). On the other hand, $A$ type chromosomes may be produced by pericentric inversion from $T$ type as observed in $L$. straminea and $L$. aurea. Other types, $M^{\prime}, T^{\prime}, m$ and $a$, were derivatives of standard $A$ type chromosomes as mentioned in foregoing text. These derived types were also observed in many animals and plants.

The occurrence of fission in the course of karyotype evolution is rather sporadic than fusion, but clear evidence of centromeric fission which produces very stable telocentric chromosomes has been reported in the cultured cells of Chinese hamster (Kato et al. 1973). The karyotype of the Mauritious black rats, $2 n=42$, was apparently evolved from the karyotype of the Oceanian black rats, $2 n=38$, by centric fission of two pairs of small metacentric chromosome (Yoshida et al. 1979). Similar type of species differentiation by centric fission has been reported in some taxa such as the mole rats (Wahrman et al. 1969), the prairie dogs (Nadler and Harris 1967), the root voles (Fredga and Bergström 1970), Japanese raccoon dogs (Yoshida and Wada 1984), and others. Todd (1970) suggested that this type of karyotype transformation was related to explosive speciation and adaptive radiation of the mammalia. In the case of Australian ants, the fission hypothesis was in better accord with the data than the fusion hypothesis (Imai et al. 1977).

In flowering plants, similar type of centric fission has also been reported in many species. Strid (1968) found a cytorace haviong $2 n=14$ in one population of Nigera doerfleri. Two homologous metacentrics in the karyotype of the standard cytorace $(2 n=12)$ were missing in this race and they were replaced by two pairs of telocentric chromosomes. The karyotypic mutants found in Crocus minimus on Corsica Island were produced by centromeric fission of some metacentric chromosomes (Brighton 1978). Similar type of centromeric fission which produces stable telocentrics has been reported in many taxa such as Spiraea filipendula (Darlington 1956), Tradescantia commelinoides (John and Lewis 1968), Miersia chiliensis (Cave and Bradley 1943), Nothoscordum fragrans (Levan and Emsweller 1938, Sato and Asano 1951), Paphiopedilum spp. (Karasawa and Saito 1982), Oxalis dispar (Marks 1957), and so forth.

On the other hand, formation of $A$ type chromosomes from $T$ or $T^{\prime}$ type is also common in both animals and plants. In this connection, Imai and Maruyama (1978) have stated that pericentric inversion is statistically "directional". Moreover, in the karyotype of Rattus rattus, it was observed that $T$ or $T^{\prime}$ type chromosomes changed into $A$ type chromosomes by pericentric inversion. At first, this derived $A$ type chromosome retained $\mathrm{C}$-banding positive centromeric region observed in the original $T$ or $T^{\prime}$ type chromosome, but it lost this region in the following generations (Yoshida and Sagai 1975). This situation somewhat resembles the case of Lycoris.

Though there may be no loss of DNA content in the course of centromeric fission, some quantities of DNA are lost in greater or lesser degree by noncentromeric fission which is immediately followed by pericentric inversion of translocation as pointed out by many authors (Stebbins 1971, White 1973). Therefore, the DNA content of the genomes evolved by such ways is less than that of the original ones.

In Lycoris, as reported by Nishikawa et al. (1979), the DNA content of the genomes composed of $M$ and $T$ type chromosome was larger than that composed of $A$ type chromosome alone. This fact seems to support to apply the fission hypothesis to the karyotype evolution of Lycoris. Indeed, many cases indicating the trends toward reduction in the total chromosome length or DNA content per genome accompanied by morphological specialization and adaptation to different habitats were known (Price 1976). For example, it was well demonstrated in Crepis (Babcock 1947), Microseris bigelovii group (Price and Bachmann 1975), 
Scilla bifolia group (Greilhuber 1979), Medicago sect. Intertextae (Schlarbaum et al. 1966). Similar decrement of DNA content accompanied by specialization in evolutionary process was reported in many animals. Hinegardner and Rosen (1972) studied DNA contents of 275 species of bony fish and they demonstrated that highly specialized fish tend to have less DNA per cell than the more generalized or less evolved fish of the same phyletic group. Bachmann and Rheinsmith (1973) obtained similar result studying the genome size of fourtytwo species of Pacific Crustaceae. These facts suggest that the species carrying large genome size may have potentiality of differentiation. Marvelously high DNA content of the genomes of some living fossils such as lungfish and mud-puppy is very interesting in this connection.

On the basis of the karyological data mentioned above, the author prefers fission hypothesis, the line I, rather than fusion hypothesis, the line II and III (Fig. 2).

However, as a matter of course, the directionality of karyotype evolution in the genus Lycoris can not be decided by the present karyomorphological study alone. Namely, there is not without a slim possibility of recent occurrence of tandem "growth" in $M$ ' type chromosomes. Likewise, $T^{\prime}$ type chromosomes may change into $T$ type getting proximal heterochromatic block by tandem "growth". Moreover, two $T$ type chromosomes may fuse into one $M$ type chromosome. In this case, heterochromatic blocks must denaturate into euchromatic ones. Therefore the author reconsiders this problem of the directionality at karyogeographic point of view, because the distribution of plants is usually regarded as it reflects their evolutional processes.

2) Karyogeographic consideration

The family Amaryllidaceae sensu Hutchinson (1973) has worldwide distribution, but the majority of the members are restricted in two continents, Africa and South America. In Africa, $29.2 \%$ genera of the family are known and $43.8 \%$ in South America, while there is only $4.2 \%$ (4 genera) in Eastern Asia where the genus Lycoris is distributed. Such distributional pattern of the family is very interesting viewed in the theory of plate tectonics or continental drift, and it may be suggestive for startlingly ancient origin of the Amaryllidaceae.

The distribution center of Lycoris is supposed to be subtropical southern China such as Fuchen, Kuangtong and Hunan province (Traub 1958). Moreover, most of the species having the genome which consists of $M$ and $T$ type chromosomes are found in these regions and not in northern warm temperate zone, in where the hardy species having the genome composed of $A$ type chromosomes are found. This suggests that the genomes consisting of $M$ and $T$ type chromosomes are ancestral ones adapted for subtropical genial climate, while the genomes consisting of $\boldsymbol{A}$ type chromosome alone are derivatives which is adapted to frosty and snowy northern climate.

The genomes consisting of $M$ and $T$ type chromosomes which are very similar to those of $L$. traubii have been known in some genera of the Amaryllidaceae such as Miersia, Tristagma, Nothoscordum and what not. In Miersia chilensis, two cytoraces were reported. The one has $2 \mathrm{n}=20=2 M+18 T$ (Cave and Bradley 1943) and the other has $2 \mathrm{n}=12=10 M+2 T$ (Poso and Zoellner 1976). While, $2 \mathrm{n}=8=6 M+2 T$ was found in Tristagma bivale, $T$. berteria and $T$. patagonicum, and $2 \mathrm{n}=16=12 M+4 T$ was in $T$. nivale (Crosa 1981). Crosa (1975) also obbserved $2 \mathrm{n}=10=6 M+4 T$ in three species of Nothoscordum. They are $N$. hirtellum, $N$. vittatum and $N$. felipponei. Moreover, the C-banding pattern of $M$ and $T$ type chromosomes of $N$. fragrans (Sato et al. 1979, 1980) bears striking resemblance to that of L. traubii (Kurita 1986). These genera having $M+T$ type genomes are chiefly or restrictively distributed in the South American Continent, and Lycoris is the only example of Eurasian genus having such genomes. On the other hand, the homogeneous karyotype consisting of $A$ type chromosome alone is now only known in Lycoris which grows in a restrictive small area of Asia. But somewhat similar karyotypes were reported in some taxa of other families. For example, Homeria 
papillosa of Iridaceae has $2 \mathrm{n}=12=12 \mathrm{~A}$ (Goldblatt 1980). This may be a case of the convergence. These facts suggest that the genome consisting of $M$ and $T$ type chromosomes is an ancient relic and $A$ type chromosomes are derivatives in the genus Lycoris.

As to the direction of karyotype evolution of Lycoris, therefore, the fission hypothesis may be most probable (Fig. 6). Namely, a fission at the centromeric region of an original $M$ type chromosome yielded two $T$ type chromosomes, and then these chromosomes lost their proximal heterochromatic block and changed into $A$ type by means of pericentric inversion in consecutive order. Consequently the genomes composed of eleven $A$ type chromosomes were resulted from the genome consisting of five $\mathrm{M}$ type and one $T$ type chromosomes; and $M^{\prime}$ $T^{\prime}, a$ and $m$ type chromosomes were produced from $A$ type chromosomes by various structural changes such as Robertsonian fusion, translocation, deficiency and so forth (Fig. 6). This is an example of the karyotypic orthoselection sensu White (White 1973). Judging from the facts mentioned above, the primary basic chromosome number of Lycoris may be six $\left(x_{1}=6\right)$, and a haploid number of eleven in some species may be a derived secondary basic chromosome number $\left(\mathrm{x}_{2}=11\right)$.

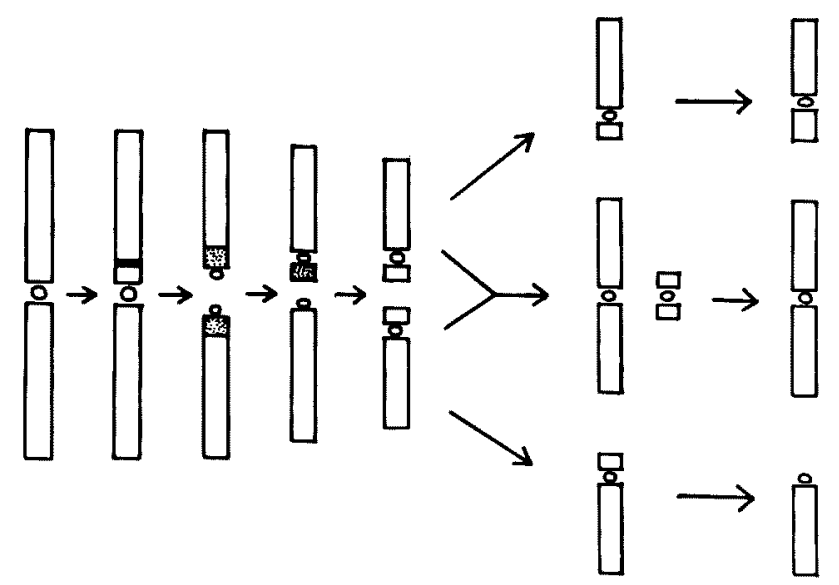

Fig. 6. Most probable trend of karyotype evolution in the genus Lycoris. Dotted parts indicate heterochromatic segments.

\section{Conclusion}

The karyotypes and their variation patterns in fifteen taxa of Lycoris have been studied minutely, and the author concluded that the genome consisting of five $M$ and one $T$ type chromosomes was ancestral. In the course of the karyotype evolution, $M$ type chromosomes changed successively into $T$ type chromosomes by centromeric fission, and then these $T$ type chromosomes were transformed into $A$ type by pericentric inversion. Therefore, the genome composed of eleven $A$ type chromosomes is a derivative. Other type of chromosome, $M^{\prime}, T^{\prime}$, $a$ and $m$, were apparently produced from $A$ type by various chromosomal mutations such as Robertsonian fusion, translocation, deficiency and inversion (Fig. 1). So, the fission hypothesis (Fig. 6) is considered to be most probable for the karyotype evolution of Lycoris.

Karyophytogeographical study also supports this view strongly. Most species having the genome consisting of $M$ and $T$ type chromosomes are grown restrictively in subtropical southern China, the center of distribution of the genus. Moreover, the $M+T$ type genomes which are very similar to those of Lycoris were known in Miersia, Tristagma, Nothoscordum and Zoellnerallium, and $T$ type chromosomes were found in Brodieae and Triteleia. Most of these 
genera belonging to Allioideae of the family are distributed restrictively in South America, but a few grows in both Central and North America. On the other hand, the genome purely composed of the $A$ type chromosome is only known in Lycoris which is found in a restricted small area of eastern Asia. Therefore, the $M+T$ type genome may be ancestral.

\section{Acknowledgement}

The author is indebted to many people for their helpful comments and criticisms. Special thanks go to Prof. Dr. M. Ono of Tokyo Metropolitan University for his interest and guidance in the preparation of this paper. The author also wishes to thank Dr. M. Nishida, Dr. T. Yamazaki, Dr. Y. Kuroki, Dr. T. Tachikawa, Dr. M. Takamiya, Dr. Y. Hiraki, Dr. M. Suzuki, Dr. H. Sudzuki, Mr. K. Minamidani, Mr. H. Higa, Mr. A. Mitsui, Mr. H. Shimizu and the late Mr. Y. Kato for their helpful supplies of many materials.

\section{References}

Babcock, E. B. 1947. The genus Crepis I and II. Univ. Calif. Publ. Bot. 21 and 22: 1030 pp.

Bachmann, K. and Rheinsmith, E. C. 1973. Nuclear DNA amount in Pacific Crustaceae. Chromosoma 43: 225-236.

Brighton, C. A. 1978. Telocentric chromosomes in Corsican Crocus L. (Iridaceae). Plant Syst. Evol. 129: 299-314.

Bose, S. 1966. Karyotype alteration in L. chinensis. Sci. Cult. 32: 144-145.

Britten, R. J. and Kohne, D. E. 1967. Nucleotide sequences repetition in DNA. Carnegie Inst. Wash. Year Book 65: 78-106.

- and - 1969. Implications of repeated nucleotide sequences. In "Handhook of Molecular Cytology" Ed. A. Lima-de-Faria, North-Holland Publ. Co. Amst.

Cave, M. S. and Bradley, M. V. 1943. Alteration of chromosome number in Miersia chilensis. Amer. J. Bot. 30: 142-149.

Chiarelli, A. B. and Capanna, E. 1973. Cytotaxonomy and Vertebrate Evolution. Academic Press, London.

Crosa, O. 1975. Zoellnerallium, un género nuevo para la tribu Allieae (Liliaceae). Darwinia 19: $331-334$.

- 1975. Las especies unifloras del género Nothoscordum Kunth y el género Ipheion Rafinisque de la tribu Allieae (Liliaceae). Dawrinia 19: 335-344.

- 1981. Los chromosomas de cinco especies del género Tristagma (Liliaceae). Darwinia 23: 361-366.

Darlington, C. D. 1956. Chromosome Botany. Allen and Unwin, London.

- 1963. Chromosome Botany and Origin of Cultivated Plants. Hafner Publ. Co., London.

Flory, W. S. 1977. Overview of chromosome evolution in the Amaryllidaceae. Nucleus 20: 70-88.

Fredga, K. and Bergström, U. 1970. Chromosome polymorphism in the root vole (Microtus oeconomus). Hereditas 66 : 145-153.

Goldblatt, P. 1980. Unveven diploid chromosome numbers and complex heterozygosity in Homeria. Syst. Bot. 5: $337-340$.

Greilhuber, J. W. 1979. Evolutionary changes of DNA and heterochromatin amount in Scilla bifiora group (Liliaceae). Plant Syst. Evol. Suppl. 2: 263-280.

Hinegardner, R. and Rosen, D. E. 1972. Cellular DNA content and the evolution of teleostean fishes. Amer. Naturalists 106: 621-644.

Hsu, T. C. and Arrighi, F. E. 1971. Distribution of constitutive heterochromatin in mammalian chromosomes. Chromosoma 34: 243-254.

Hutchinson, J. 1973. The Families of Flowering Plants, Arranged According to a New System Based on Their Probable Phylogeny. Oxford Clarendon Press.

Imai, H. T., Crozier, R. H. and Taylor, R. W. 1977. Karyotype evolution in Australian ants. Chromosoma 59: 341-393.

- and Maruyama, T. 1978. Karyotype evolution by pericentric inversion as a stochastic process. J. Theor. Biol. 70: 253-261.

Inariyama, S. 1951a. Cytological studies in the genus Lycoris (I). Sci. Rep. T. B. D. Sect. B. 6: 74-100. - 1951b. Cytological studies in the genus Lycoris (II). Sci. Rep. T. B. D. Sect. B. 7: 103-157.

John, B. and King, M. 1983. Population cytogenetics of Atractmorpha similis I. C-band variation. Chromo- 
soma 88: $57-68$.

- and Lewis, K. R. 1978. The Chromosome Complement. Protoplasmatologia VI. A. Wien, SpringerVerlag.

Jones, K. 1978. Aspects of chromosome evolution in higher plants. Recent Advance Bot. 6: $119-194$.

- and Kenton, A. 1981. Contribution to the cytotaxonomy of the Commerinaceae. Chromosome evolution in Tradescantia section Cymbispatha. Bot. J. Linn. Soc. 83: 157-188.

Karasawa, K. and Saito, K. 1982. A revision of the genus Paphiopedilum (Orchidaceae). Bull. Hiroshima Bot. Garden 5: 1-69.

Kato, H., Sagai, T. and Yoshida, T. H. 1973. Stable telocentric chromosomes produced by centric fission in Chinese hamster cells in vitro. Chromosoma 40:183-192.

Koyama, M. 1967. Chromosome pairing in the genus Lycoris (I). Ann. Rep. Doshisha Women's Coll. 18: 411-418.

- 1978. Chromosome pairing in the genus Lycoris (II). Ann. Rep. Doshisha Women's Coll. 29: $272-282$.

Kurita, S. 1986. Variation and evolution in the karyotype of Lycoris, Amaryllidaceae I. General karyomorphological characteristics of the genus. Cytologia 51 : 803-815.

- 1987a. Ditto II. Karyotype analysis of ten taxa among which seven are native in China. Cytologia 52: $19-40$.

- 1987b. Ditto III. Intraspecific variation in the karyotype of L. traubii Hayward. Cytologia 52: 117-128.

- 1987c. Ditto IV. Intraspeciflc variation in the karyotype of L. radiata (L'Hérit.) Herb. and the origin of this triploid species. Cytologia 52: 137-149.

- 1988c. Ditto V. Intrapouplational and/or intraspecific variation in the karyotype of $L$. sanguinea Maxim. var. sanguinea. Plant Species Biol. (in press).

- 1988a. Ditto VI. Intrapopulational and/or intraspecific variation in the karyotype of L. sanguinea Maxim. var. kiushiana Makino and var. koreana (Nakai) Koyama. Cytologia 53: 307-321.

Kuroki, Y. 1964. Chromosome of Brodiaea uniflora Engl. CIS 5: 9-11.

Levan, A. and Emsweller, S. L. 1938. Structural hybridity in Nothoscordum fragrans. J. Hered. $29: 291-294$.

Macgregor, H. C. 1978. Some trends in the evolution of very large chromosomes. Phil. Trans. Roy. Soc. London $B .283$ : 309-318.

Marks, G. E. 1957. The cytology of Oxalis dispar Brown. Chromosoma 8: 650-670.

Nadler, C. F. and Harris, K. E. 1967. Chromosomes of North American prairie dog Cynomys induvicianus. Experimenta 23: 41-50.

Nishikawa, K., Furuta, Y. and Endo, N. 1979. Consideration of the chromosome evolution on the basis of nuclear DNA content and total chromosome length in Lycoris. Jap. J. Genet. 54: 387-396.

Poso, O. and Zoellner, O. 1976. Miersia chiliensis. Lindley. plant Life 32: 118-120.

Price, H. J. 1976. Evolution of DNA content in higher plants. Bot. Rev. 42: 27-52.

- and Bachmann, K. 1975. DNA content and evolution in the Microseridinae. Amer, J. Bot. $62: 262-267$.

Sato, D. and Asano A. 1951. Basikaryotype analysis in Nothoscordum fragrans $(2 \mathrm{n}=19)$. Bot. Mag. Tokyo 64: 209-215.

Sato, S., Ohta, S. and Kuroki, Y. 1979. Two types of colordifferentiated C-banding positive segments in chromosomes of Nothoscordum fragrans, Liliaceae. Cytologia 44: 715-725.

-, - and - 1980. Heteromorphic appearance of acrocentric nucleolus arganiger in Hothoscordum fragrans. Cytologia 45: 87-96.

Schimke, R. T. 1981. Gene amplification and drug resistance. Sci. Amer. (Jap. Ed.) 11: 9-19.

Schlarbaum, S. E., Small, E. and Johnson, L. B. 1966. Karyotype evolution, morphological variability and phylogeny in Medicago sect. Intertextae. Pl. Syst. Evol. $145: 203-222$.

Smith, G. P. 1976. Evolution of repeted DNA sequences by unequal crossover. Science 191: 528-533.

Sparrow, A. H. and Nauman, A. F. 1976. Evolution of genome size by DNA doublings. Science 192: 524529.

Stebbins, G. L. 1971. Chromosome Evolution in Higher Plants. Edward Arnold Ltd., London.

Strid, A. 1968. Stable telocentric chromosomes formed by spontaneous misdivision in Nigera doerfleri (Ranunculaceae). Bot. Not. 121: 153-164.

Tanaka, R. 1967. A comparative karyotype analysis in Haplopappus gracilis $(2 \mathrm{n}=8)$. Cytologia $32: 542-552$.

Todd, N. B. 1970. Karyotypic fissioning and canid phylogeny. J. Theor. Biol. 26: 445-480.

Traub, H. P. 1958. Two new Lycoris species. Plant Life 14: 42-44.

Wahrman, J., Gitein, R. and Nevo, E. 1969. Mole rat Sparax; Evolutionary significance of chromosome variation. Science 164: 82-84.

White, M. J. D. 1973. Animal Cytology and Evolution. Camb. Univ. Press, Cambridge.

Wurster, M. J. and Benirschke, K. 1970. Indian Muntjac, Muntiacus muntjak, a deer with low diploid chromo- 
some number. Science 168: 1364-1366.

Yoshida, T.H. 1980. Karyotype of Indian spiny mouse resulted from tandem fusion of some of the house mouse chromosomes. Cytologia 45: 753-760.

- 1983. Chromosome differntiation and species evolution in Rodent. Chromosomes in Evolution of Eukaryot Group I. NCE. New York. pp. 147-176.

- and Sagai, T. 1975. Variation of C-bands in the chromosomes of several subspecies of Rattus rattus. Chromosoma 50: 283-300.

- and Wada, M. 1984. Karyotype differentiation of the Japanese raccoon dog due to the B-chromosomes and Robertsonian fission. La Kromosomo II-37: 1165-1166.

-, Kato, H., Tsuchiya, K., Moriwaki, K., Ochiai, Y. and Monty, J. 1979. Mauritius type black rats with peculiar karyotype derived from Robertsonian fission of small metacentrics. Chromosoma 75: 51-59. 